\title{
Risk Behaviour and Youth Resilience-Based on Demographic Profile
}

\author{
Jungjungan Simorangkir, Marina Letara Nababan, May Rauli Simamora, Winarti \\ Agustina \\ Institut Agama Kristen Negeri Tarutung \\ E-mail address: jsimorangkir271@gmail.com; E-mail address: marinaletara@gmail.com, \\ E-mail address: may88simamora@,gmail.com; E-mail address: winarti1708@,gmail.com
}

\begin{abstract}
Youth who has the ability to adapt and survive in difficult times have a high level of resilience. This study aims to look at the dominant Behavior of adolescents currently and the youth resilience based on gender, types of school, and school major. The sample in this study was 264 high school teenagers in Indonesia. This study used a quantitative method with two design which is a cross-sectional survey and comparative studies. The results showed some of the most risk behaviors seen by students were smoking (84.09\%), fighting parents (68.49\%), skipping school (60.23\%), fighting teachers and school principals $(55.68 \%)$, and fighting between students (54.17\%). The risk behaviors that were rarely seen by teenage students were drugs (5.68\%), free sex (4.55\%). Stealing (43.18\%) and excessive drinking (41.67\%) have moderate popularity. Also, there was no significant difference in resiliencebased on gender, type of school, and school major. These studies provide an overview of schools of the importance of the availability of Counseling Guidance teachers in providing guidance services and resilience materials.
\end{abstract}

Keywords: Resiliency, risk behavior, and youth

\section{INTRODUCTION}

Based on a search on Google regarding the primary and highest problems faced by adolescents today are problems of being accepted by the surrounding environment, stress/life pressure, depression and anxiety, self-harm (consuming drugs, alcohol, and hurting yourself), bullying, desensitization, free sex, disrespect, trust, and motivation (Waddle, 2020). The WHO (World Health Organization) also reports that 10 to $20 \%$ of adolescents worldwide experience mental disorders, both internalizing and externalizing. WHO even mentions that teenagers all over the world struggle with various emotional and behavioral problems that can affect their success and well-being (Huang, Chen, Cheung, Greene, \& $\mathrm{Lu}, 2019)$. The key to dealing with these problems is to have the ability to resilience that can reduce the effects of internal and external problems (Huang, Chen, Cheung, Greene, \& Lu, 2019). The topic of resilience has always been an important research topic for scientists, policymakers, and other stakeholders to disclose aspects to encourage positive development results (Hupp \& Jewell, 2019). Resilience has defined as the ability to cope with unexpected dangers, learn to bounce back, and the ability to withstand pressure from the surrounding environment (Wen, Chen, Yang, Kang, \& Zhang, 2019).

The initial observations were made to determine the level of resilience to 33 high school adolescents in the north by distributing questionnaires. On the question of whether they liked the challenge, 19 people 
were confused, and three people didn't like the challenge. Two students answered that they would not rise again after being faced with illnesses, injuries, or other misfortunes, and eleven other students were confused about their answers. This observation means that students are not yet capable enough to face challenging problems. There is also one person who doesn't have a good relationship with his family. All students have the belief that God helps them in facing the problems that exist.

\section{LITERATURE REVIEW}

In developing research related to resilience, some have tried to look at the comparison of the level of resilience of male adolescents and adolescent girls, and the result is that male adolescent has a significantly higher level of resilience (Erdogan, Ozdogan, \& Erdogan, 2015). Research by (Namy et al., 2017) relates resilience to Behavior that arises from having a low level of resilience, namely violence, trying drugs or alcohol, suicide, low academic achievement, and anti-social behavior. This study identifies risk behaviors that result from a low level of resilience so that further analysis is needed to see which risk behavior is more dominant. Bulut et al. also, in their research, said that demographics have an influence on the level of a person's resilience, and further research is needed to understand the unique needs and development of adolescents in various cities (Bulut et al., 2018). So, based on the problems of some of the relevant studies and these preliminary observations, this study was conducted to indicate risk adolescent behaviors that arise from low levels of resilience.

\section{RESEARCH METHODOLOGY}

\section{Study design}

The method used in this research is a descriptive quantitative method with two design approaches. The first design is a cross-sectional survey design that looks at and analyzes information about the risk behaviors that occur in the environment around adolescents. Second, a comparative study that compares resilience based on demographic profiles, namely gender, school type, and school major.

\section{Sampling and Data Collection}

The population of this study was high school students enrolled in public and private schools on Sumatra island, the northern part of Indonesia. The research sample was 264 youth (70 boys and 194 girls) to an average age level of 16 years six months (XI and XII classes). There were 177 participants from science classes, and 87 people majoring in social studies. Participants in this study were collected through an online technique (Zhang et al., 2017) called convenience-sampling, in which the research sample was determined based on students' willingness to fill out a questionnaire in a Google Form link that was sent via the school's WhatsApp group.

The questionnaires consist of questions related to student identity (such as gender, class, major, home address, place of birth date), a resilience scale compiled by Connor \& Davidson (2003) which was slightly modified into 27 items with a Cronbach alpha value of 0.895 and all valid items. The final question in the questionnaire is "Choose some of the following risk behaviors that you see and know about what your friends are doing in your surroundings. (Can choose more than 1)". The researcher provided 11 answer choices and one blank answer to be filled in by the students in which it may not be included in the choices. Risk behaviors that are being the answer choices include drugs, smoking, excessive drinking (for example, tuak, beer, etc.), free sex, skipping school, stealing, fighting against students or gangs, getting pregnant outside of marriage, abortion, fighting against parents and/or against the teacher or principal.

\section{Statistical Analysis}

Statistical analysis in this study was conducted with the help from the Statistical Package for Social Science program (SPSS) 24th version. The results of data analysis with survey design are presented in 
the form of frequency and percentage tables. Meanwhile, the design of a comparative study of resilience is based on demographic profiles using one-way analysis of variance (ANOVA).

\section{FINDING AND DISCUSSION}

The frequency and percentage of the risk behavior in youth are presented in Table 1. The most risk behaviors seen by high school youths are smoking (84.09\%), fighting against their parents $(68.94 \%)$, skipping school (60.23\%), fighting against teachers or school principal $(55.68 \%)$, and fighting against other students or gangs $(54.17 \%)$. Furthermore, risk behaviors most rarely seen by high school youths are abortion $(1.52 \%)$, free sex $(4.55 \%)$, drugs $(5.68 \%)$, and pregnancy outside of marriage $(14.77 \%)$. Other risk behaviors, such as excessive drinking (41.67\%) and stealing (43.18\%), have moderate popularity. Other risk behaviors (4.92\%) reported by high school youth include lying, bullying, playing games, playing gambling, eating without praying, not doing homework, accusing, fighting, and being careless.

Table 1. Frequency and Percentage of Risk Behaviours.

$\begin{array}{lcc} & \mathrm{f} & \% \\ \text { Drugs } & 15 & 5.68 \\ \text { Smoking } & 222 & 84.09 \\ \text { Alcohols (e.g., tuak, beer, etc.) } & 110 & 41.67 \\ \text { Free sex } & 12 & 4.55 \\ \text { Skipping school } & 159 & 60.23 \\ \text { Stealing } & 114 & 43.18 \\ \text { Fighting against other friends or gangs } & 143 & 54.17 \\ \text { Pregnant outside marriage } & 39 & 14.77 \\ \text { Abortion } & 4 & 1.52 \\ \text { Fighting against parents } & 182 & 68.94 \\ \text { Fighting against teachers or school principal } & 147 & 55.68 \\ \text { Other risk behaviors } & 13 & 4.92\end{array}$

The descriptive statistics of resilience score data received minimum score $(\min =36)$, maximum ( $\max$ $=135)$, average $(\mathrm{M}=108.31)$ and standard deviation $(\mathrm{SD}=12.81)$. The category level is determined by three categories, including low, medium, and high. The result of the resilience score calculation can be seen in Table 2. The result of the analysis showed that $14.4 \%$ of the participants' scores are included in the low category, $68.6 \%$ are in the medium category, and $17 \%$ are in the high category.

Table 2. Youth Resilience within Categories

$\begin{array}{cccc}\text { Category } & \begin{array}{c}\text { Category } \\ \text { Formulas }\end{array} & \text { Frequency } & \% \\ \text { Low } & \mathrm{X}<\mathrm{M}-1 \mathrm{SD} & 38 & 14,4 \\ \text { Medium } & \mathrm{M}-1 \mathrm{SD} \leq \mathrm{X}< & 181 & 68,6 \\ & \mathrm{M}+1 \mathrm{SD} & & \\ \text { High } & \mathrm{M}+1 \mathrm{SD} \leq \mathrm{X} & 45 & 17\end{array}$

Table 3. The differences in youth resilience scores based on gender, type of school, and school major

\begin{tabular}{lcrrrrr} 
Demographic Profile & & Mean & \multicolumn{1}{l}{ SD } & df & t & $p$ \\
\hline Gender & Male & 107.70 & 11.87 & 262 & $-0,467$ & 0,641 \\
\hline & Female & 108.53 & 13.16 & & &
\end{tabular}


Proceeding on International Conference of Education in the New Normal Era (ICEIAKN)

Vol. 1 (1), 26-30

Risk Behaviour and Youth Resilience-Based on Demographic Profile

Jungjungan Simorangkir, Marina Letara Nababan, May Rauli Simamora, Winarti Agustina

\begin{tabular}{lcccccr}
\hline Type of School & Public & 108.89 & 12.94 & 262 & 1,168 & 0,244 \\
\hline & Private & 106.85 & 12.45 & & & \\
\hline Major & Science & 107.37 & 12.71 & 262 & $-1,709$ & 0,089 \\
\hline & Social & 110.22 & 12.89 & & &
\end{tabular}

The differences in youth resilience scores based on gender, type of school, and school major are presented in Table 3. First, looking at Gender, there was no significant difference in the resilience score between male (Mean=107.7, $\mathrm{SD}=11.87$ ) and female (Mean=108.53, $\mathrm{SD}=13.16), \mathrm{t}=-0.467, \mathrm{p}=0.641$ $(p>.05)$. Second, there is no significant difference in the resilience score between public school (Mean=108.89, $\mathrm{SD}=12.94)$ and private school (Mean=106.85, $\mathrm{SD}=12.45), \mathrm{t}=1.168, \mathrm{p}=0.244(\mathrm{p}>.05)$. Finally, no significant differences were found between science (Mean=107.37, $\mathrm{SD}=12.71$ ) and social (Mean=110.22, $\mathrm{SD}=12.89)$ in terms of their resilience scores, $\mathrm{t}=-1,709, \mathrm{p}=0,089(\mathrm{p}>.05)$.

The primary purpose of this study was to investigate the dominant risk behavior and resilience based on gender, types of school, and school major among youth. In this study, the most risk behavior seen by high school youths in their surroundings is smoking. Smoking is linked to other risk behaviors because heavy smokers tend to be involved with other risk behaviors such as alcohol and marijuana consumption, drinking, sexual intercourse (Charrier et al., 2019). One of the reasons smoking is the dominant choice; youths tend to choose the wrong strategy to reduce stress levels by smoking. In this study, we found that there was no significant difference in resilience-based on gender, type of school, and school major. There is no significant difference in the resilience score between males and females. This result, in line with other studies, showed that there is no significant difference in resilience level between males and females (Ravera, Iniesta-Arandia, Martin-Lopez, Pascual, \& Bose, 2016).

Resilience contributes to reducing adolescent aggressive behavior (Khurana et al., 2018). Therefore, resilience is needed to protect youths. Besides, emotional and behavioral problems in adolescents can be intervened by involving mindfulness and life skills training to manage stressful situations experienced more healthily to increase resilience (Huang, Chen, Cheung, Greene, \& Lu, 2019) because stress in youth is related to the level of adulthood resilience (Daniel et al., 2020). So, Liu et al. recommended that positive and healthy schools and families be established as important protective factors for youth resilience (Liu, Kia-Keating, Nylund-Gibson, \& Barnett, 2020). Also, psychotherapy that focuses on resilience is highly recommended to protect adolescents because they may have a bad childhood experience that has the potential to cause psychological distress that affects adolescents to use drugs in the future (Fuchs, Glaude, Hansel, Osofsky, \& Osofsky, 2020).

\section{CONCLUSION AND FURTHER RESEARCH}

Youths who can adapt and survive in difficult times tend to have a high level of resilience. The implication of the findings of this study relates to the importance of guidance and counseling teachers' availability in North Tapanuli schools in providing services regarding guidance and resilience materials. Resilience is essential for adolescents to learn during their development (Burt \& Rosenberg, 2020). Also, local governments need to provide counseling or anti-smoking campaigns in schools as one of the strategies to prevent risk youth behaviors.

\section{REFERENCES}

Bulut, N. S. et al., 2018. Living in difficult conditions: an analysis of the factors associated with resilience in the youth of a disadvantaged city. Psychiatry and Clinical Psychopharmacology, pp. $1-11$. 
Burt, K. B. \& Rosenberg, E. R., 2020. Resilience. The Encyclopedia of Child and Adolescent Development, pp. 1-11.

Charrier, L. et al., 2019. Cigarette Smoking and Multiple Health Risk Behaviors: A Latent Class Regression Model to Identify a Profile of Young Adolescents. Risk Analysis, pp., 1771-1782.

Daniel, R. et al., 2020. Resilience in the Setting of Adverse Childhood Experiences: A Cross-Sectional Study. Clinical Pediatrics, pp. 1-5.

Erdogan, E., Ozdogan, O. \& Erdogan, M., 2015. University Students' Resilience Level: The Effect of Gender and Faculty. Soc. Behav. Sci., Volume 186, p. 1262-1267.

Fuchs, R. et al., 2020. Adolescent risk substance use behavior, posttraumatic stress, depression, and resilience: Innovative considerations for disaster recovery. Substance Abuse, pp. 1-8.

Huang, C. et al., 2019. Resilience, emotional problems, and behavioral problems of adolescents in China: Roles of mindfulness and life skills. Health Soc Care Community, pp. 1-9.

Hupp, S. \& Jewell, J., 2019. The Encyclopedia of Child and Adolescent Development. United States: John Wiley \& Sons.

Khurana, A. et al., 2018. Media violence exposure and aggression in adolescents: A risk and resilience perspective. Aggressive Behavior, pp. 1-12.

Liu, S. R., Kia-Keating, M., Nylund-Gibson, K. \& Barnett, M. L., 2020. Co-Occurring Youth Profiles of Adverse Childhood Experiences and Protective Factors: Associations with Health, Resilience, and Racial Disparities. Am J Community Psychol, pp. 173-186.

Namy, S. et al., 2017. Gender, violence, and resilience among Ugandan adolescents. Child Abuse Negl., p. 303-314.

Ravera, F. et al., 2016. Gender perspectives in resilience, vulnerability, and adaptation to global environmental change. Ambio, pp. 235-247.

Waddle, J., 2020. 0 Most Common Problems Teens Face in 2020. [Online]

Available at: https://parentology.com/10-most-common-problems-teens-face-in-2019/

Wen, M. et al., 2019. Resilience-based component importance measures. Int J Robust Nonlinear Control., pp. 1-11. 